\title{
Perhitungan Kebutuhan Rak Penyimpanan Dokumen Rekam Medis Dan Luas Ruang Filing Di Rumah Sakit Tahun 2020-2024
}

\section{Calculation Of The Requirement For Medical Record Documents Filing Shelf And The Vast Of Filing Room At The Hospital In 2020-2024}

\author{
Hikmawan Suryanto ${ }^{1}$ \\ Azizah Munawwarah 2 \\ Barokatul Auliyatun Fitriyana ${ }^{3}$ \\ 1,2) Administrator Kesehatan; Dinas Kesehatan, Pengendalian Penduduk, dan Keluarga \\ Berencana Kota Probolinggo \\ Jl. Suroyo No. 58, Kota Probolinggo \\ 3) Jurusan Rekam Medis dan Informasi Kesehatan, Institut Ilmu Kesehatan \\ Bhakti Wiyata Kediri \\ Jl. KH. Wachid Hasyim No. 65 Kota Kediri \\ E-mail : hikmawan.suryanto.hs@gmail.com
}

\begin{abstract}
The increase in patient visits resulted in an increase in medical record documents that must be stored, so that the storage rack became full. The purpose of this research is to determine the calculation of the need for storage racks for medical record documents and the area of filing space at the hospital in 2020-2024. The method used in this research is quantitative descriptive which was conducted at the hospital in November 2019-April 2020. The population and sample used were medical record documents. The sampling technique used was purposive sampling. The result of this study is that patient visits in the 2015-2019 period tended to increase which led to an increase in medical record documents, so that there were additional medical record documents that had to be stored. The last retention that the hospital did was in 2014. The need for storage racks in 2020-2024 is 20 racks, the hospital currently has 18 racks. The conclusion of this research is that the area of filing space required to store 20 racks with roll o'pack model is $32.24 \mathrm{~m}^{2}$. The suggestion from this research is that hospitals should make a retention schedule so that retention can be carried out regularly to provide a place for new medical record documents. Added 2 storage racks in order to meet the needs of storage racks. Separating inactive storage racks in different spaces and providing a divider between the officer's work space and the filing space.
\end{abstract}

Keywords: calculation of shelf requirements, medical record document, filing space area

\begin{abstract}
Abstrak
Meningkatnya kunjungan pasien mengakibatkan bertambahnya dokumen rekam medis yang harus disimpan, sehingga rak penyimpanan menjadi penuh. Tujuan peneltian ini adalah mengetahui perhitungan kebutuhan rak penyimpanan dokumen rekam medis dan luas ruang filing di rumah sakit tahun 2020-2024. Metode yang digunakan dalam penelitian ini adalah deskriptif kuantitatif yang dilakukan di rumah sakit pada November 2019-April 2020. Populasi dan sampel yang digunakan adalah dokumen rekam medis. Teknik sampling yang digunakan adalah purposive sampling. Hasil dari penelitian ini adalah kunjungan pasien pada periode tahun 2015-2019 cenderung meningkat yang menyebabkan bertambahnya dokumen rekam medis, sehingga bertmbah pula dokumen rekam medis yang harus disimpan. rumah sakit
\end{abstract}


terakhir melakukan retensi pada tahun 2014. Kebutuhan rak penyimpanan tahun 2020-2024 sebanyak 20 rak, rumah sakit saat ini memiliki 18 rak. Kesimpulan dari penelitian ini yaitu luas ruang filing yang dibutuhkan untuk menyimpan 20 rak dengan model roll o'pack adalah 32,24 $\mathrm{m}^{2}$. Saran dari penelitian ini adalah rumah sakit sebaiknya membuat jadwal retensi agar retensi dapat terlaksanan secara rutin untuk menyediakan tempat dokumen rekam medis yang baru. Melakukan penambahan 2 rak penyimpanan agar dapat memenuhi kebutuhan rak penyimpanan. Memisahkan rak penyimpanan inaktif di ruang yang berbeda dan memberi sekat antara ruang kerja petugas dengan ruang filing.

Kata kunci: perhitungan kebutuhan rak; dokumen rekam medis; luas ruang filing

\section{Pendahuluan}

Kesehatan merupakan kebutuhan pokok bagi masyarakat dan setiap orang berhak mendapatkan kesehatan untuk meningkatkan derajat kesehatan yang optimal. Berbagai upaya peningkatan kesehatan masyarakat di Indonesia saat ini tengah gencar dilakukan oleh pemerintah. Rumah sakit sebagai penyedia sarana kesehatan harus selalu memberikan pelayanan kesehatan kepada seluruh lapisan masyarakat agar terwujud derajat kesehatan yang optimal (Cahyaningrum dan Woko, 2019).

Menurut Undang-Undang Republik Indonesia Nomor 44 Tahun 2009 tentang Rumah Sakit, rumah sakit adalah institusi pelayanan kesehatan yang menyelenggarakan pelayanan kesehatan perorangan secara paripurna yang menyediakan pelayanan rawat inap, rawat jalan dan gawat darurat. Pelayanan kesehatan paripurna adalah pelayanan kesehatan yang meliputi promotif, preventif, kuratif, dan rehabilitatif. Dalam pelaksanaannya sebagai pemberi pelayanan kesehatan, rumah sakit harus menyelenggarakan pengelolaan rekam medis yang baik (Dinia dan Nudji, 2017).

Rekam Medis adalah berkas yang berisikan catatan dan dokumen tentang identitas pasien, pemeriksaan, pengobatan, tindakan dan pelayanan lain yang telah diberikan kepada pasien pada sarana pelayanan kesehatan (Hatta, 2014). Rekam medis merupakan hal yang bersifat rahasia dan wajib disimpan dengan baik. Kerahasiaan isi pada dokumen rekam medis diperkuat dengan Permenkes RI Nomor 269 tahun 2008 tentang Rekam Medis pasal 8 yang menyebutkan bahwa rekam medis pasien rumah sakit wajib disimpan sekurang-kurangnya untuk jangka waktu lima tahun terhitung sejak pasien terakhir berobat atau dipulangkan. Untuk menjaga kerahasiaan dokumen rekam medis harus ditunjang dengan adanya tempat penyimpanan yang layak.

Setiap rumah sakit memiliki unit pengelolaan dokumen rekam medis yang meliputi penyelenggaraan penyimpanan serta pengeluaran dokumen rekam medis dari tempat penyimpanan untuk melayani permintaan atau peminjaman karena pasien datang, berobat, atau untuk keperluan lainnya (Rosita dan Prihantoro, 2019). Salah satu unit rekam medis yang menunjang dalam pelayanan rekam medis adalah ruang penyimpanan (filing) yang memadai. Filing adalah kegiatan menyimpan (storage) dokumen rekam medis untuk mempermudah pengambilan kembali (retrieval) dokumen rekam medis yang disimpan dalam rak penyimpanan (Yuliani, 2016). Ada enam unsur yang berkaitan dengan penyimpanan, yaitu kemudahan akses, berkualitas, keamanan terjamin (Security), fleksibilitas, dapat dihubungkan dengan berbagai sumber dan efisien (Hatta, 2014).

Sistem penyimpanan di rumah sakit menggunakan sistem penyimpanan sentralisasi dimana dokumen rekam medis rawat inap dan rawat jalan disimpan dalam satu folder. Rak penyimpanan di rumah sakit sudah tidak 
bisa menampung dokumen rekam medis yang terus bertambah. Dibuktikan dengan masih adanya dokumen rekam medis yang disimpan dalam kardus-kardus dan terselip dalam dokumen lain yang menyebabkan petugas kesulitan dalam mencari dokumen rekam medis serta rentan terjadinya kerusakan fisik pada dokumen rekam medis tersebut. Hal ini tidak sesuai dengan pernyataan Roach, et al. (2006) bahwa rekam medis merupakan bukti penting dan catatan terperinci mengenai pelayanan yang diberikan kepada pasien. Oleh karena itu, dokumen rekam medis harus disimpan dengan baik karena memiliki nilai hukum bagi penyedia layanan kesehatan dan pasien. Dokumen rekam medis hendaknya disusun secara sistematik untuk memudahkan pencarian dan kompilasi data (Hatta, 2014).

Berdasarkan hasil penelitian yang dilakukan Fanny dan Azhari (2019) bahwa dokumen rekam medis yang telah diolah kemudian disimpan di rak penyimpanan dokumen rekam medis. Apabila rak penyimpanan sudah melebihi daya tampung maka diperlukan perencanaan atau pengadaan rak penyimpanan dokumen rekam medis kembali. Menurut penelitian yang dilakukan Ritonga, ZA dan Ritonga, NA (2018) dalam merencanakan atau pengadaan kembali rak penyimpanan harus mengacu pada jumlah dokumen rekam medis yang akan disimpan dan memperhatikan luas ruang suatu ruangan yang digunakan.

\section{Metode}

Desain penelitian yang digunakan dalam penelitian ini adalah desain deskriptif kuantitatif. Desain penelitian deskriptif kuantitatif adalah desain penelitian untuk melihat gambaran fenomena yang terjadi dalam populasi tertentu untuk menjawab pertanyaan penelitian dengan cara mengikuti kaidah keilmuan. (Masturoh dan Anggita, 2018).
Populasi dan sampel yang digunakan adalah dokumen rekam medis dengan menggunakan teknik purposive sampling.

\section{Hasil dan Pembahasan}

Jumlah Kunjungan Pasien Di Rumah Sakit Tahun 2015-2019

Berikut data kunjungan pasien tahun 2015-2019 di rumah sakit :

Tabel 1. Jumlah Kunjungan Pasien di Rumah Sakit Tahun 2015-2019

\begin{tabular}{cc}
\hline Tahun Kunjungan & Jumlah \\
\hline 2015 & 10363 \\
2016 & 13757 \\
2017 & 14009 \\
2018 & 16726 \\
2019 & 17810 \\
\hline TOTAL & 72665
\end{tabular}

Sumber : Data Primer

Berdasarkan tabel 1, diketahui bahwa jumlah kunjungan pasien di Rumah Sakit tahun 2015-2019 sebanyak 72665 kunjungan. Selama kurun waktu 5 tahun kunjungan pasien cenderung meningkat setiap tahunnya. Menurut Sudra (2017), kunjungan adalah setiap kedatangan pasien ke suatu fasilitas pelayanan kesehatan untuk mendapatkan layanan tersedia sesuai dengan masalah kesehatan yang dimiliki. Setiap pasien yang mendapatkan pelayanan di suatu fasilitas pelayanan kesehatan akan dibuatkan rekam medis untuk mendokumentasikan riwayat kesehatannya. Dengan demikian, semakin banyak pasien yang berkunjung maka semakin banyak pula dokumen rekam medis yang harus disimpan. Menurut penelitian yang dilakukan oleh Ritongan dan Ritongan (2018) yang menyatakan bahwa seiring bertambahnya pasien setiap harinya, maka semakin bertambah pula dokumen rekam medis dan ketebalan dokumen rekam medis pada rak penyimpanan. 
Pelaksanaan Retensi Dokumen Rekam Medis di Rumah Sakit

Salah satu kegiatan yang dimiliki unit rekam medis adalah filing. Bagian filing memiliki beberapa tugas pokok, diantaranya menyusutkan dokumen rekam medis sesuai dengan ketentuan yang ditetapkan sarana pelayanan kesehatan. Berdasarkan hasil wawancara dengan informan, pelaksanaan retensi di rumah sakit terakhir kali dilaksanakan pada tahun 2014. Retensi di rumah sakit dilakukan pada dokumen rekam medis yang telah disimpan selama 5 tahun sejak kunjungan terakhir pasien.

Dokumen rekam medis yang telah diretensi disebut dokumen rekam medis inaktif yang diletakkan terpisah dengan dokumen rekam medis aktif. Jumlah dokumen rekam medis yang telah diretensi tidak diketahui. Hal ini menurut informan disebabkan catatan yang berisi tentang dokumen rekam medis yang diretensi hilang.

Pelaksanakan retensi di rumah sakit berpedoman pada SPO tentang penyusutan/retensi dokumen rekam medis. Akan tetapi dalam pelaksanaan retensi, rumah sakit belum memiliki jadwal retensi. Hal ini dibuktikan dengan jawaban pada saat wawancara, informan menyatakan bahwa rumah sakit terakhir kali melaksanakan retensi adalah pada tahun 2014. Menurut Departemen Kesehatan RI (2006), menyatakan bahwa salah satu elemen yang diperlukan pada pelaksanaan retensi adalah jadwal retensi dokumen rekam medis yang wajib dimiliki oleh setiap sarana pelayanan kesehatan. Akibat tidak dilaksanakannya retensi secara berkala, banyak dokumen rekam medis yang tercecer karena rak penyimpanan sudah penuh. Hal tersebut tidak sesuai dengan pernyataan Hatta (2014) bahwa dokumen rekam medis hendaknya disusun secara sistematik agar memudahkan dalam pencarian dan kompilasi data. Berdasarkan penelitian yang dilakukan oleh Fanny dan Azhari (2019), pelaksanaan retensi dapat menyediakan tempat untuk dokumen rekam medis yang baru. Sehingga dokumen rekam medis yang tercecer dapat diletakkan pada tempat yang tersedia setelah dilakukannya retensi.

Kebutuhan Rak Penyimpanan Dokumen Rekam Medis di Rumah Sakit Tahun 2020-2024

Berdasarkan hasil observasi, rak penyimpanan yang digunakan di rumah sakit yaitu menggunakan rak terbuka berbahan kayu dan rak roll o'pack. Rak terbuka berbahan kayu digunakan untuk menyimpan dokumen rekam medis inaktif, sedangkan rak roll o'pack digunakan untuk menyimpan dokumen rekam medis aktif. Berikut hasil observasi rak penyimpanan dokumen rekam medis di ruang filing rumah sakit:

Tabel 2. Hasil Observasi Perhitungan Kebutuhan Rak Penyimpanan DRM

\begin{tabular}{clc}
\hline No & \multicolumn{1}{c}{ Indikator } & \multicolumn{1}{c}{ Hasil } \\
\hline 1 & Tebal DRM & $0,7(\mathrm{~cm})$ \\
2 & $\begin{array}{l}\text { Panjang Rak } \\
\text { Penyimpanan DRM }\end{array}$ & $2(\mathrm{~m})$ \\
3 & Model Rak & $\begin{array}{l}\text { a. } \\
\text { Rak Terbuka } \\
\text { berbahan kayu }\end{array}$ \\
& & b. $\begin{array}{l}\text { Rak roll o'pack } \\
\text { Posisi tidur } \\
\text { (Horizontal) }\end{array}$ \\
\hline
\end{tabular}

Sumber : Data Primer

Rak penyimpanan yang saat ini digunakan belum memiliki subrak dengan kapasitas penyimpanan yang berbeda. Setiap 1 rak penyimpanan memiliki 6 shaft dengan panjang $200 \mathrm{~cm}$, lebar $40 \mathrm{~cm}$, dan tinggi $180 \mathrm{~cm}$. Berikut adalah perhitungan kebutuhan rak penyimpanan dokumen rekam medis berdasarkan rumus Siswati (2018) :

a) Siapkan data yang diperlukan

Perhitungan kebutuhan rak penyimpanan dokumen rekam medis 
ini dihitung untuk jangka panjang yakni 5 tahun kedepan. Untuk mengetahui berapa dokumen rekam medis yang akan disimpan 5 tahun kedepan, perlu diketahui berapa pertumbuhan dokumen setiap tahunnya yang didapat dari jumlah kunjungan pasien setiap tahunnya baik rawat jalan maupun rawat inap selama 5 tahun. Berikut adalah data jumlah dokumen rekam medis yang disimpan pada tahun 2014-2019:

Tabel 3. Jumlah Dokumen Rekam Medis Tahun 2014-2019

\begin{tabular}{cc}
\hline Tahun Kunjungan & Jumlah \\
\hline 2014 & 9437 \\
2015 & 10363 \\
2016 & 13757 \\
2017 & 14009 \\
2018 & 16726 \\
2019 & 17810 \\
\hline
\end{tabular}

Sumber : Data Primer

Cara menghitung pertumbuhan dokumen rekam medis setiap tahun ialah sebagai berikut :

\section{$\frac{\Sigma \text { DRM Tahun } A-\Sigma \text { DRM Tahun } B}{\Sigma D R M}$ Tahun $B$}

Keterangan :

Tahun A : Tahun yang dicari

Tahun B : Tahun sebelumnya

Berdasarkan rumus diatas, didapatkan hasil sebagai berikut :

Tabel 4. Hasil Perhitungan Pertumbuhan DRM Tahun 2015-2019

\begin{tabular}{cc}
\hline Tahun & Pertumbuhan Drm (\%) \\
\hline 2015 & $9,8 \%$ \\
2016 & $32,7 \%$ \\
2017 & $1,8 \%$ \\
2018 & $19,4 \%$ \\
2019 & $6,5 \%$ \\
\hline Rata-Rata & $14,04 \%$ \\
\hline
\end{tabular}

Sumber : Data Primer
Untuk mengetahui perkiraan dokumen rekam medis yang akan disimpan tahun 2020-2024, dengan cara :

\section{$\bar{x}$ Pertumbuhan DRMx D DRM Tahun B}

Keterangan :

Tahun A : Tahun yang dicari

Tahun B : Tahun sebelumnya

Setelah diketahui berapa dokumen yang akan disimpan, jumlahkan dengan jumlah dokumen tahun sebelumnya. Berdasarkan rumus diatas didapatkan hasil sebagai berikut :

Tabel 5. Hasil Perhitungan Pertumbuhan DRM Tahun 2020-2024

\begin{tabular}{cc}
\hline Tahun & Jumlah Drm \\
\hline 2020 & 20311 \\
2021 & 23163 \\
2022 & 26478 \\
2023 & 30196 \\
2024 & 34436 \\
\hline
\end{tabular}

Sumber : Data Primer

Jadi diketahui perkiraan dokumen rekam medis yang akan disimpan sebanyak 34436 dokumen rekam medis.

b) Model rak yang akan dibeli

Model rak yang akan dibeli yaitu rak roll o'pack. Rak 6 shaft dengan panjang $200 \mathrm{~cm}$, lebar $40 \mathrm{~cm}$, dan tinggi 180 $\mathrm{cm}$.

c) Ketebalan dokumen rekam medis

Banyaknya tebal dokumen rekam medis yang diukur menyesuaikan jumlah dokumen rekam medis yang dijajarkan pada satu shaft rak penyimpanan. Berikut cara menghitung rata-rata ketebalan dokumen rekam medis : 
Rata-rata tebal DRM :

$$
\begin{aligned}
& =\frac{\sum \text { Tebal DRM }}{\text { Banyaknya DRM }} \\
& =\frac{198 \mathrm{~cm}}{304 \text { dokumen rekam medis }} \\
& =0,7 \mathrm{~cm}
\end{aligned}
$$

Berdasarkan hasil perhitungan diatas, dapat dihitung berapa kapasitas yang dimiliki setiap rak penyimpanan dengan cara :

Kapasitas rak penyimpanan DRM :

$$
=\frac{\text { Panjang rak penyimpanan } D R M}{\text { Rata-rata ketebalan } D R M}
$$$$
=\frac{200 \mathrm{~cm}}{0,7 \mathrm{~cm}}
$$

$=286$ dokumen rekam medis

Kapasitas rak penyimpanan DRM

$=286 \times 6$ shaft

$=1716$ dokumen rekam medis

Jadi 1 rak penyimpanan dapat menyimpan 1716 dokumen rekam medis.

d) Posisi penyimpanan yang digunakan Posisi penyimpanan dokumen rekam medis di rumah sakit adalah posisi tidur. Posisi ini menyesuaikan dengan bentuk horizontal dari map dokumen rekam medis.

e) Hitung kebutuhan rak penyimpanan

Kebutuhan rak penyimpanan DRM :

$=\frac{\text { Jumlah DRM yang akan disimpan }}{\text { Kapsitas rak penyimpanan DRM }}$

$=\frac{34436}{1716}$

$=20 \mathrm{rak}$

Rak penyimpanan yang dibutuhkan rumah sakit selama tahun 2020-2024 adalah 20 rak. Saat ini rumah sakit sudah memiliki 18 rak roll o'pack. Maka dibutuhkan 2 rak tambahan untuk memenuhi kebutuhan selama 5 tahun kedepan yakni tahun 2020-2024.
Berdasarkan hasil perhitungan kebutuhan rak penyimpanan dokumen rekam medis di rumah sakit, didapatkan hasil perhitungan sejumlah 20 rak. Perhitungan kebutuhan rak penyimpanan untuk 5 tahun mendatang yakni tahun 2020-2024. rumah sakit telah memiliki 18 rak penyimpanan. Maka diperlukan adanya tambahan rak penyimpanan dokumen rekam medis sebanyak 2 rak. Penelitian yang dilakukan oleh Fanny dan Azhari (2019) menyatakan bahwa penambahan rak penyimpanan dokumen rekam medis sangat penting direncanakan agar dokumen rekam medis pada masa yang akan datang terlihat lebih rapi dan tidak tercecer di lantai atau di tata di tempat lain. Sehingga dapat memudahkan petugas dalam pencarian dan mengembalikan dokumen yang akan atau sudah diambil.

Rak yang diusulkan adalah rak roll o'pack dengan panjang $200 \mathrm{~cm}$, lebar $40 \mathrm{~cm}$ dan tinggi $180 \mathrm{~cm}$. Menurut Siswati (2018), model rak yang akan dibeli dan ketebalan dokumen rekam medis dapat mempengaruhi jumlah rak yang dibutuhkan. Pemilihan rak roll o'pack diperkuat dengan pernyataan Sudra (2017) bahwa rak roll o'pack merupakan modifikasi dan pengembangan dari rak terbuka, bedanya rak roll o'pack mudah digeser karena memiliki rodal atau rel. Akan tetapi rak roll o'pack membutuhkan biaya pengadaan yang lebih mahal. 
Kebutuhan Luas Ruang Filing Di Rumah Sakit Tahun 2020-2024

Berdasarkan hasil observasi, Ruang filing rumah sakit terletak di lantai 2 dengan luas $84,64 \mathrm{~m}^{2}$. Berikut hasil observasi ruang filing di rumah sakit:

Tabel 6. Hasil Observasi Perhitungan Luas Ruang Filing

\begin{tabular}{clc}
\hline No & \multicolumn{1}{c}{ Indikator } & Hasil \\
\hline 1 & Panjang Ruang & $9,2(\mathrm{~m})$ \\
2 & Lebar Ruang & $9,2(\mathrm{~m})$ \\
3 & Luas Ruang & $84,64\left(\mathrm{~m}^{2}\right)$ \\
\hline
\end{tabular}

Sumber : Data Primer

Diketahui bahwa ruang filing di rumah sakit sempit. Jarak antar rak penyimpanan berkisar antara 50-60 cm yang hanya bisa dilewati oleh satu orang saja. Terdapat dokumen rekam medis yang terletak di lantai, karena rak penyimpanan sudah tidak dapat menampung dokumen rekam medis lagi. Berikut denah ruang filing di rumah sakit :

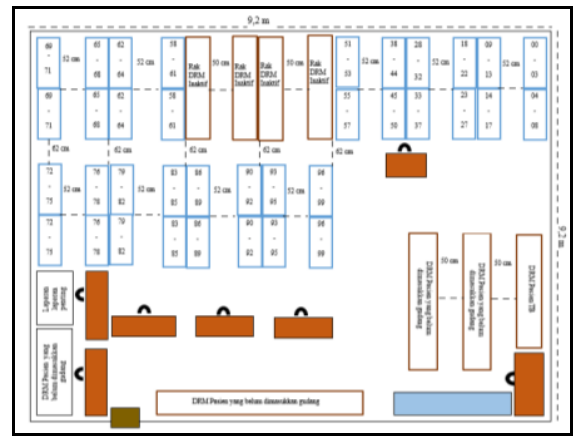

Gambar 1. Denah Ruang Filing Rumah Sakit

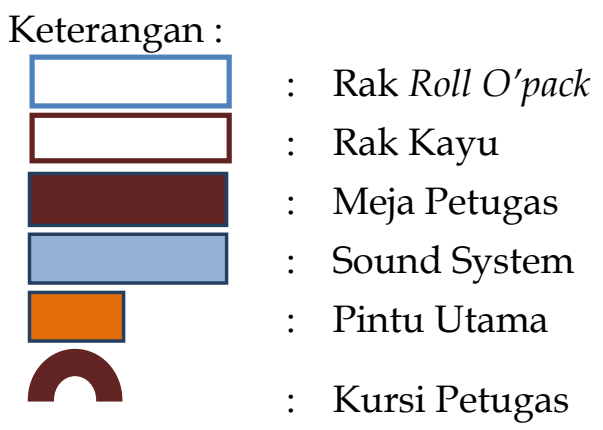

Berdasarkan gambar 1 tersebut, ruang filing di rumah sakit terdiri atas ruang penyimpanan dokumen rekam medis aktif, dokumen rekam medis inaktif, dokumen rekam medis yang siap dimusnahkan dan pengolahan data. Ruang filing di rumah sakit tidak memungkinkan untuk menambah rak penyimpanan. Keadaan ini belum sesuai dengan pernyataan Rustiyanto (2011) bahwa ruang filing dokumen rekam medis aktif dan inaktif sebaiknya disendirikan karena hal ini akan lebih memudahkan petugas dalam mengambil dokumen rekam medis yang masih aktif dan melaksanakan pemusnahan dokumen rekam medis. Menurut penelitian yang dilakukan oleh Dinia dan Nudji (2017), ruang filing dan ruang kerja perekam medis harus terpisah baik ruangan yang berbeda atau diberi sekat. Pemisahan ini bertujuan untuk menjaga keamanan DRM yang bersifat rahasia.

Maka diperlukan adanya perhitungan kebutuhan luas ruang filing yang akan digunakan untuk penambahan rak penyimpanan dengan tata letak yang benar. Rak penyimpanan yang diusulkan adalah rak roll o'pack dengan panjang 200 $\mathrm{cm}$ dan lebar $40 \mathrm{~cm}$.

Berikut perhitungan kebutuhan luas ruang filing dengan cara :

$$
\begin{aligned}
& \text { Panjang ruang } \\
& =(\text { Jarak antar rak } \times \text { Jumlah })+(\text { Panjang } \\
& \quad \text { Rak }) \\
& =(90 \mathrm{~cm} \times 2)+(40 \mathrm{~cm} \times 12) \\
& =180 \mathrm{~cm}+480 \mathrm{~cm} \\
& =660 \mathrm{~cm} \\
& =6,6 \mathrm{~m} \\
& \text { Lebar ruang } \\
& =(\text { Jarak antar rak } \times \text { Jumlah })+(\text { Panjang } \\
& \quad \text { Rak }) \\
& =(90 \mathrm{~cm} \times 1)+(200 \mathrm{~cm} \times 2) \\
& =90 \mathrm{~cm}+400 \mathrm{~cm} \\
& =490 \mathrm{~cm} \\
& =4,9 \mathrm{~m}
\end{aligned}
$$


Luas ruang

$=$ Panjang Ruang $x$ Lebar Ruang

$=6,6 \times 4,9$

$=32,24 \mathrm{~m}^{2}$

Perhitungan kebutuhan luas ruang filing di rumah sakit tahun 2020-2024 menyesuaikan jumlah rak yang akan digunakan, ukuran rak dan jarak antar rak. Dari hasil perhitungan di atas maka berikut susulan kebutuhan ruas filling di rumah sakit tahun 2020 - 2024 yang digambarkan dalam denah di bawah ini.

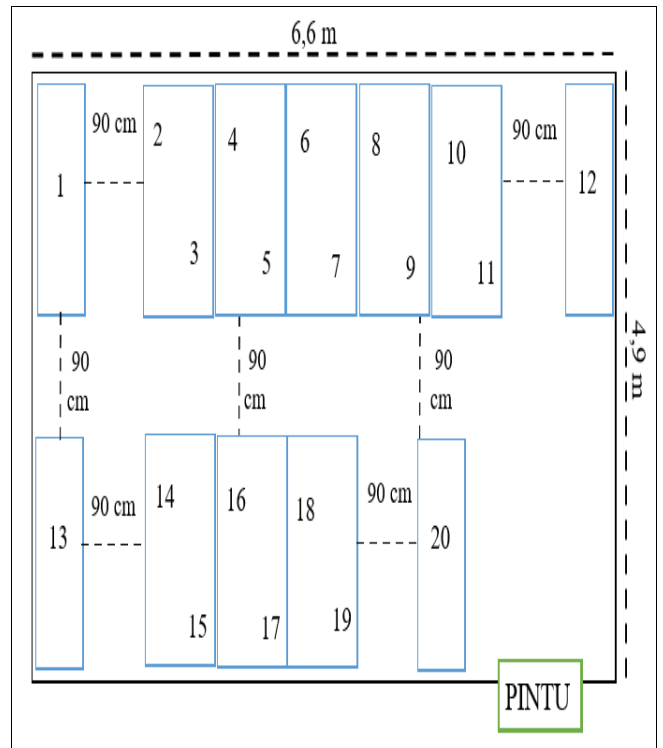

Gambar 2. Denah Perhitungan Kebutuhan Ruang Filling Rumah Sakit Tahun 2020-2024

Hasil perhitungan kebutuhan luas ruang filing di rumah sakit tahun 2020-2024 dengan rak roll o'pack adalah 32,34 m². Menurut Sudra (2017), Kelebihan penggunaan rak roll o'pack adalah penggunaan ruangan lebih hemat karena rak memiliki roda atau rel yang dapat memudahkan rak untuk digeser. Dengan ini tidak diperlukan adanya jarak antar rak, cukup disediakan satu atau dua jarak. Sedangkan rak yang lain dapat dihimpitkan jika tidak diperlukan.

Jarak antar rak di ruang filing rumah sakit sekitar $50-60 \mathrm{~cm}$. Hal ini belum sesuai dengan teori yang tertera pada
Departemen Kesehatan RI (2006) bahwa jarak antar dua rak untuk lalu lalang dianjurkan selebar $90 \mathrm{~cm}$. Berdasarkan hasil penelitian Putri, dkk (2014), pengukuran jarak antar rak berguna untuk mempermudah dalam lalu lalang petugas rekam medis dalam pengambilan maupun penyimpanan dokumen rekam medis secara bersamaan tanpa adanya hambatan. Sehingga pelayanan yang diberikan dalam penyiapan DRM saat dibutuhkan tetap terjaga kualitasnya.

\section{Simpulan dan Saran}

1. Kunjungan pasien di rumah sakit periode tahun 2015-2019 terus mengalami peningkatan peningkatan dengan rata rata 14533 kunjungan pertahun.

2. Pelaksanaan retensi di rumah sakit terakhir kali dilakukan pada tahun 2014.

3. Kebutuhan rak penyimpanan dokumen rekam medis di rumah sakit tahun 2020-2024 sebanyak 20 rak. rumah sakit telah memiliki 18 rak, sehingga hanya membutuhkan tambahan 2 rak untuk memenuhi kebutuhan 5 tahun mendatang.

4. Luas ruang filing yang dibutuhkan di rumah sakit adalah $32,24 \mathrm{~m}^{2}$ dan jarak antar rak penyimpanan yang digunakan adalah $90 \mathrm{~cm}$.

5. Sebaiknya diberlakukan jadwal retensi agar pelaksanaan retensi dokumen rekam medis lebih teratur sehingga dapat menyediakan tempat untuk dokumen rekam medis baru.

6. Sebaiknya dilakukan penambahan rak penyimpanan sebanyak 2 rak agar dapat memenuhi kebutuhan rak penyimpanan dokumen rekam medis selama 5 tahun mendatang. Model rak yang digunakan adalah rak roll o'pack yang memiliki 6 shaft dengan panjang $200 \mathrm{~cm}$ dan lebar $40 \mathrm{~cm}$ dan tinggi 180 $\mathrm{cm}$. 
7. Sebaiknya dilakukan pemisahan ruangan antara dokumen rekam medis aktif dan inaktif agar dapat memberikan cukup ruang jika ada penambahan rak penyimpanan dokumen rekam medis.

8. Sebaiknya dilakukan pemisahan antara ruang penyimpanan dengan ruang kerja petugas rekam medis agar keamanan dokumen rekam medis lebih terjaga.

\section{Ucapan Terima Kasih}

Terima kasih disampaikan kepada pimpinan rumah sakit dan staf rekam medis rumah sakit yang telah membantu dalam proses penelitian.

\section{Daftar Pustaka}

Cahyaningrum dan Woko (2019, March). Kebutuhan dan Desain Rak Penyimpanan Dokumen Rekam Medis Berdasarkan Antropometri Petugas Filing Di RSUI Banyubening Boyolali Tahun 2018-2022. Prosiding Call For Paper SMIKNAS.

Departemen Kesehatan Republik Indonesia Direktorat Jendral Pelayanan Medik. (2006). Pedoman Pengelolaan Rekam Medis Rumah Sakit di Indonesia. Jakarta: Departemen Kesehatan Republik Indonesia.

Dinia dan Nudji. (2017, October). Perancangan Ulang Tata Letak Ruang Unit Rekam Medis Dalam Peningkatan Produktivitas Kerja Perekam Medis di Rumah Sakit Paru Surabaya. Jurnal Manajemen Kesehatan, 3(1), 39-40.

Fanny dan Azhari. (2019, Ferbuary). Analisis Kebutuhan Rak Penyimpanan Dokumen Rekam Medis Aktif Di Rumah Sakit Umum PKU Muhammadiyah Delanggu Tahun 2022. Jurnal Ilmiah Rekam Medis dan Informasi Kesehatan, 9(1), 37-38.
Hatta, Gemala. (2014). Pedoman Manajemen Informasi Kesehatan di Sarana Pelayanan Kesehatan. Jakarta: Universitas Indonesia (UI-Press).

Masturoh dan Anggita. (2018). Metodologi Penelitian Kesehatan. Jakarta: Kementerian Kesehatan Republik Indonesia.

Peraturan Menteri Kesehatan Republik Indonesia Nomor 269 Tahun 2008 Tentang Rekam Medis. Jakarta: Kementerian Kesehatan Republik Indonesia.

Putri, A.P., Triyanti, E., Setiadi, D. (2014, October). Analisis Tata Ruang tempat Penyimpanan Dokumen Rekam Medis Pasien Ditinjau Dari Aspek Antropometri Petugas Rekam Medis. Jurnal Manajemen Informasi Kesehatan Indonesia, 3(1), 46-47.

Ritonga, ZA dan Ritonga, NA. 2018. Analisa Kebutuhan Rak Penyimpanan Berkas Rekam Medis Rawat Jalan Di Rumah Sakit Umum Madani Medan. Jurnal Ilmiah Perekam dan Informasi Kesehatan Imelda. Volume(3): 417-418.

Roach, W.H., Hoban, R.G., Brocollo, B.M., Roth, A.B., Blanchard, T.P. (2006). Medical Record And The Law. Fourth Edition. Sudbury: Jones and Bartlett Publishers.

Rosita dan Prihantoro. (2019). Perencanaan Desain Rak Penyimpanan Dokumen Rekam Medis Berdasarkan Antropometri. Jurnal Rekam Medis dan Informasi Kesehatan, 17(1), 14-16.

Rustiyanto, E. (2011). Manajemen Filing Dokumen Rekam Medis dan Informasi Kesehatan. Yogyakarta: Politeknik Kesehatan Permata Indonesia.

Siswati. (2018). Manajemen Unit Kerja II Perencanaan SDM Unit Kerja RMIK. Jakarta: Kementerian Kesehatan Republik Indonesia.

Sudra, R. I. (2017). Rekam Medis. Tangerang: Universitas Terbuka. 
Undang - Undang Republik Indonesia No. 44 Tahun 2009 Tentang Rumah Sakit. Jakarta: Kementerian Kesehatan Republik Indonesia.

Yuliani, N. (2016, November). Faktor-Faktor Yang Mempengaruhi Keamanan Berkas Rekam Medis Berdasarkan Peraturan Perundang-Undangan (Studi Kasus Di Rumah Sakit Umum Daerah Sukoharjo). Jurnal Ilmiah Rekam Medis dan Informasi Kesehatan, 6(2), 55-56. 